\title{
Relationship Between $\gamma$-Glutamyltransferase $(\gamma$-GT) with High Sensitive C-Reactive Protein (hs-CRP), Oxidized (Ox-LDL) and Glutathione Peroxidase (GPx) on Coronary Heart Disease (CHD) Patient
}

\author{
Marissa Arifin ${ }^{1,4}$, Marsetio Donosepoetro², Sutomo Kasiman ${ }^{3^{*}}$
}

$\mathrm{B}$ ACKGROUND - Recent clinical studies have suggested that $\gamma$-glutamyltransferase $(\gamma$-GT) can trigger oxidative stress within the plaque. This study aimed to investigate whether serum $\gamma$-GT might be as a risk factor of coronary heart disease (CHD), and measure the associations of serum $\gamma$-GT with high sensitive C-Reactive Protein (hs-CRP), Oxidized LDL (Ox-LDL) and Glutathione Peroxidase (GPx).

METHODS: This study recruited 48 patients aged 30-70 year who underwent coronary angiography at Haji Adam Malik Medical Center at Medan between February and April 2008 and who presented at least one coronary stenosis of $>50 \%$ of the luminar diameter. The sample subjects were consecutively selected.

RESULTS: $\gamma$-Glutamyltransferase was positively associated ( $\mathrm{r}=0.546)$ with hs-CRP as a marker of chronic inflammation after careful adjustment for other established risk factors in CHD patient. But, there was no significant difference between $\gamma$-GT in male and female patients. Further, there were no correlations between $\gamma$-GT and Ox-LDL and GPx. Ratio of $\gamma$-GT/ GPx was measured as well, and it was associated with hs-CRP.

CONCLUSIONS: Ratio of $\gamma$-GT/GPx was associated with inflammation process in coronary heart disease patients.
KEYWORDS: $\quad \gamma$-glutamyltransferase $\quad(\gamma$-GT); inflammation; oxidative stress, coronary heart disease.

\section{Introduction}

In clinical practice $\gamma$-GT is commonly used as diagnostic test, in addition, it is considered to be an hepatobiliary index. Apparently in the past few decades, a lot of data reveals that $\gamma$-GT serum is a prognostic factor of death from CHD and recurrent myocardial infarction (1).

Autopsy result also shows the catalytic activity of $\gamma$-GT among the atherosclerotic plaque in cerebral, carotid and also coronary artery along with oxidized (Ox-LDL) and CD68+ in foam cell (3).

Ruttman et. Al. (2005) recruited 163.944 adult subjects in Australia during the last 17 years and showed that $\gamma$-GT serum was an independent marker of death due to cardiovascular diseases (4).

Additionally, Whitfield et. al. (2002) showed a significant correlation between serum $\gamma$-GT with Body Mass Index (BMI), lipoprotein, glucose, insulin, and blood pressure $(5,6,7)$.
${ }^{1}$ Laboratory Information Services of Prodia Clinical Laboratory, Medan

${ }^{2}$ Faculty of Medicine, University of Airlangga, Surabaya
${ }^{3}$ Departement of Cardiology, Faculty of Medicine, University of North Sumatera, Indonesia

${ }^{4}$ Post Graduate Program in Clinical Biochemisty, Hasanuddin University, Makassar 
$\gamma$-GT is a protein on the cell surface-l. This enzyme is produced by a large number of tissue. This protein is carried by lipoprotein and albumin (8). This is an enzyme that takes charge of extracellular glutathione catabolism (GSH, $\gamma$-glutamyl-cisteinyl-glycine), thus its main role as an intra-cellular anti oxidant in mammals (3).

GSH is a non-protein intracellular link attacking free radical (9). GSH is a tripeptide that contains glutamic acid, cystein and glycin. This antioxidanteffect is closely related with the cyctein molecular reduction. Intracellular content of GSH preserved by synthetic enzyme that regulates the formation of the particular tripeptide. Due to the high intracellular concentration, GSH will be taken out to the extracellular sphere. When it is located in the extracellular environment then consequently, the glutathione cellular uptake from within will decrease (10).

$\gamma$-GT will eliminate $\gamma$-glutamyl cluster from GSH, after CysGly splitting by dipeptidase membrane. Released Cystein (Cys) will be carried intracellularly and used as a substrate for de novo GSH synthesis. $\gamma$-glutamyl cycle is an important process to maintain the number of cellular GSH (11).

This enzyme involves in intra-cellular homeostasis to redraw GSH and leads to intra-cellular redox reactions (11).

Even though the role of $\gamma$-GT accumulation in atherosclerotic plaques is not yet clearly established, presumably this substance will be associated with LDL-cholesterol oxidation. Extra-cellularly, $\gamma$-GT will function as an enzyme in GSH catabolism via linking reaction between glutamate and glycine. Afterwards, it will be taken intra-cellularly and used as precursor in GSH reformation (11).

CysGly is a strong reducing agent to $\mathrm{Fe} 3+$ ion in the extracellular and also in the atherosclerosis plaque in such way that increase the $\mathrm{Fe} 2+$ production and thiol free radical. Subsequent reaction will increase the superoxide anion free radical. This particular reaction mediated by $\gamma$-GT obviously is able to catalyze the lipoprotein LDL oxidation. Stress oxidative reaction that mediated by serum $\gamma$-GT hold an important role in the atherosclerotic plaque formation and its stability (3).

Autopsy study showed that there was catalytic activity of $\gamma$-GT within atherosclerotic plaque in the cerebral, carotid and also in coronary artery in concert with LDL cholesterol oxidation and CD68+ in foam cell (3).
$\gamma$-GT also has pro-inflammatory characteristic, because it can transform leukotrine C-4 to leukotrine D-4. It also correlates positively with few cardiovascular risk factors, such as C-reactive protein (CRP) (15), fibrinogen, F2-isoprostane, and inversely related with the antioxidant quality $(15,16)$, and consequently it would need further study to see whether $\gamma$-GT can be considered as a CHD risk factor, and to see the relation with the inflammation indicator, oxidative stress and antioxidant by looking at the hs-CRP study as inflammation indicator, GPx as antioxidant indicator and Ox-LDL as indicator for oxidized LDL (16).

\section{Methods}

\section{SUBJECTS}

Men and women patients $(\mathrm{n}=60)$ aged $30-70$ years old who underwent coronary angiography at University of North Sumatera Medical Center - Haji Adam Malik - Medan North Sumatera consecutively between February 2008 and April 2008 and who showed at least one coronary stenosis of $>50 \%$ of the luminar diameter were included in this study. Main exclusion criteria patients were first diagnosis of CHD $>1$ year ago, infection between the past 3 weeks, malignant disease, acute or chronic liver disease, alcoholic, anti-coagulant, anti-inflammation and antioxidant therapy.

All subjects underwent standardized interviews. All subjects gave written informed consent and the study was approved by the ethics committee of the University of North Sumatera - Medan.

\section{DATA COLLECTION}

Venous blood was drawn in the morning under standardized condition for complete blood count and analysis of aspartate aminotransferase (AST), alanine aminotransferase (ALT), hs-CRP, $\gamma$-GT, GPx and OxLDL. In cases, blood drawing was done before the angiographic procedure. Blood from patients who showed least one coronary stenosis of $>50 \%$ of the luminar diameter was centrifuged at 3000rpm for 15 min, immediately aliquot and frozen at -20 oC until analysis at $12 \mathrm{pm}$ a clock.

Patients who have normal AST, ALT and hs-CRP $<10 \mathrm{mg} / \mathrm{dL}$ were included in this study. $\gamma$-GT serum concentration were determine by colorimetric method 
( $\gamma$-GT Dade Behring, catalog number 201682), OxLDL was determined by ELISA (Ox-LDL, Mercodia Oxidized LDL-ELISA, catalog number 10-1143-01), GPx was determined by routine enzymatic Method (GPx, Randox).

\section{STATISTICAL ANALYSIS}

Statistical analyses were performed using computer program. Data analyzed with descriptive using univariate analysis for minimum, maximum and standard deviation. Furthermore, we used non parametric analysis, the Kolmogorov - Smirnov, to assess the each variable normally distributed or not. Each variable ( $\gamma$-GT, Ox-LDL and GPx) analyzed with statistical method to show whether there are difference respond to gender (male and female), age cluster (31-40 years old; 41-50 years old; 51-60 years old; 61-70 years old), and inflammation degree (hs-CRP) $(<1 \mathrm{mg} / \mathrm{L}$ (low), 1-3 mg/L (medium) and $>3 \mathrm{mg} / \mathrm{L}$ (high)). We also used bivariat analysis the Spearman correlation to assess the correlation between $\gamma$-GT with hs-CRP, Ox-LDL and GPx. For Each variable ( $\gamma$-GT, Ox-LDL and GPx), differences between 2 groups (gender (men and women), age (31-40; 41-50; 51-60; 61-70), and inflammation levels ((hs-CRP) $(<1 \mathrm{mg} / \mathrm{L}$ (low), 1-3 $\mathrm{mg} / \mathrm{L}$ (medium) and $>3 \mathrm{mg} / \mathrm{L}$ (high)) were analyzed with Independent-Sample $\mathrm{T}$ Test when data were normally distributed and with Mann-Whitney U test when the assumption of normally was not met.

\section{Results}

\section{STUDY POPULATION}

Of these 48 patients (stable CHD), $68.8 \%$ were men and $31.3 \%$ were women. Table 1 gives more information about general and biochemical characteristic of patients.

Table 1. General and Biochemical characteristic of patients

\begin{tabular}{|l|l|l|l|l|l|c}
\hline Characteristic & N & Mean & SD & Median & Minimum & Maximum \\
\hline Age & 48 & 54.48 & 7.968 & 54.50 & 38 & 69 \\
BPS & 48 & 134.85 & 17.998 & 133.50 & 110 & 180 \\
BPD & 48 & 87.83 & 13.701 & 86.50 & 68 & 150 \\
SGOT & 48 & 28.13 & 14.945 & 23.50 & 12 & 103 \\
SGPT & 48 & 29.92 & 19.298 & 23.50 & 11 & 110 \\
Y-GT & 48 & 58.83 & 47.223 & 42.50 & 11 & 227 \\
hs-CRP & 48 & 5.983 & 3.4528 & 7.1000 & 0.3 & 10 \\
GPx & 48 & 42.765 & 11.3907 & 41.400 & 7.3 & 76.2 \\
Ox-LDL & 48 & 65.5581 & 18.01970 & 62.6200 & 25.71 & 104.98 \\
\hline
\end{tabular}

Age (year); BPS = Systolic Blood Pressure $(\mathrm{mmHg})$; BPD = Diastolic Blood Pressure $(\mathrm{mmHg})$; SGOT = Serum Glutamat Oxaloasetat Transferase (U/L); SGPT = Serum Glutamat Piruvat Transaminase (U/L); $\mathrm{Y}-\mathrm{GT}=$ Gamma-Glutamyl Transferase $(\mathrm{U} / \mathrm{L})$; hs-CRP = high se $\square$ siti $\square$ ity C Reacti $\square$ e Protei $\square$ (mg $\square$ L); GPx = Glutatio $\square$ Pero $\square$ sidase ( $\square \square$ gH $\square$ ); Ox-LDL = Oxidi $\square$ ed Lo $\square$ De $\square$ sity Li $\square$ o $\square$ rotei $\square$ ( $\square \square$ L) . 


\section{DIFFERENCES ANALYSIS}

From the data processing in a test manner for nonparametric Mann-Whitney $\mathrm{U}$, not allowed for difference value of $\gamma$-GT to the gender cluster (male and female), which is $P>0.05$. Same result also showed from the result of difference value of $\gamma$-GT from and against age cluster (31-40 years old; $41-50$ years old; 51 60 years old; 61-70 years old) by using the difference test non-parametric Kruskal-Wallis Test, showed that there are no mean difference $\gamma$-GT against the age cluster with the value $\mathrm{P}>0.05$.

According to test result, differences between the value of $\gamma$-GT with the inflammation degree (hsCRP) $(<1 \mathrm{mg} / \mathrm{L}$ (low), $1-3 \mathrm{mg} / \mathrm{L}$ (medium) and $>3$ $\mathrm{mg} / \mathrm{L}$ (high)) by using difference non-parametric test Kruskal-Wallis Test, shows that are mean differences the value of $\gamma$-GT on the three inflammation degree $(\mathrm{P}<0.05)$. Even though there are mean difference the value of $\gamma$-GT on the particular degree, but there are still few variable point that is still overlap, it need further study that are more sensitive to see a clear difference, by using Post Hoc-LSD test. This test result shows that a cluster of high inflammation degree $(>3$ $\mathrm{mg} / \mathrm{L}$ ) shows a mean difference, mean while a cluster of low inflammation degree shows the contrary.

According to the Difference Test result by using Independent - Sample T Test, shows that the amount of GPx respond to gender variation (male and female), age cluster (31-40 years old; 41-50 years old; 51-60 years old; 61-70 years old), and inflammation degree(hs-CRP) (<1 mg/L (low), 1-3 mg/L (medium) and $>3 \mathrm{mg} / \mathrm{L}$ (high)), shows that there are no mean differences to the amount of GPx due to the gender variation $(\mathrm{P}>0.05)$ and age cluster $(\mathrm{P}>0.05)$. In contrary a further study on the age cluster by using Post HocLSD, shows that there are mean difference to the amount of GPx with the 51-60 age cluster and the 6170 age cluster. A mean difference also shows on the inflammation degree $(\mathrm{P}>0.05)$.

From the reference value of Ox-LDL $(26-117 \mathrm{U} / \mathrm{L})$ turn out to be there are none of the participant has an Ox-LDL amount that exceeds the reference value. From the test result from the Difference Test, the value of Ox-LDL against the gender variation (male and female), age cluster (31-40 years old; 41-50 years old; 51-60 years old; 61-70 years old), and inflammation degree(hs-CRP) ( $<1 \mathrm{mg} / \mathrm{L}$ (low), 1-3 mg/L (medium) and $>3 \mathrm{mg} / \mathrm{L}$ (high)) shows that there are no mean difference of the amount of Ox- LDL according to gender variation $(\mathrm{P}>0.05)$ and age cluster $(\mathrm{P}>0.05)$ and also to inflammation degree and mean differences between $\gamma$-GT with inflammation levels (low, mild and high) (table 2).

\section{Table 2. Differences between each variable with genders, ages, and inflammation levels}

\begin{tabular}{|c|c|c|c|}
\hline Variable & $\begin{array}{c}\text { Genders } \\
\text { (Men \& Women) }\end{array}$ & $\begin{array}{c}\text { Ages (yrs) } \\
(31-40) \\
(41-50) \\
(51-60) \\
(61-70)\end{array}$ & $\begin{array}{c}\text { Inflammation Levels } \\
\text { hs-CRP } \\
(<1 \mathrm{mg} / \mathrm{L}) \\
(1-3 \mathrm{mg} / \mathrm{l}) \\
(>3 \mathrm{mg} / \mathrm{L})\end{array}$ \\
\hline V-GT (U/L) & $P=0.107$ & $P=0.198$ & $P=0.001^{*}$ \\
\hline Hs-CRP (mg/L) & $P=0.525$ & $P=0.734$ & - \\
\hline Ox-LDL (U/L) & $P=0.680$ & $P=0.831$ & $P=0.388$ \\
\hline GPX (U/L) & $P=0.777$ & $P=0.816$ & $P=0.705$ \\
\hline
\end{tabular}

* = significant $(p<0.05)$ 


\section{BIVARIATE CORRELATION ANALYSIS}

Spearman Correlation Test carried out to see the relation between $\gamma$-GT with hs-CRP, Ox-LDL and GPx. The Test Correlation test result shows in the Table3 below.

\section{Table 3. Correlation between y-GT with hs-CRP, Ox-LDL and GPx}

\begin{tabular}{l|c|c}
\hline \multicolumn{1}{|c|}{ Variable } & $\begin{array}{c}\text { Y-GT } \\
\text { Correlation }(\mathbf{r})\end{array}$ & $\begin{array}{c}\text { Y-GT } \\
\text { Significant }(\mathbf{p})\end{array}$ \\
\hline hs-CRP & $0.546^{* *}$ & 0.000 \\
Ox-LDL & 0.220 & 0.133 \\
GPX & -0.036 & 0.870 \\
\hline
\end{tabular}

A linear mean relation came up in the result. From Table 3 above we can see that relation between $\gamma$-GT and hs-CRP ( $\mathrm{r}=0.546)$, mean while between $\gamma$-GT and Ox-LDL and also between $\gamma$-GT and GPx not showing any mean linear relation (Figure 30 and 31). From the above data, we can see that between $\gamma$-GT and GPx shows a inverse relation $(\mathrm{r}=-0.036)$, not yet showing a mean linear relation.

\section{CATEGORICAL CORRELATION ANALYSIS}

Since Spearman Test result between $\gamma$-GT and Ox-LDL and GPx not showing a mean relation according to the early hypothesis, the next step taken is to clustering the categorical data for each variables, become low value cluster and high value cluster, this cluster done according to median.

Table 4. Categorical correlation between y-GT with hs-CRP, Ox-LDL and GPx

\begin{tabular}{|c|c|c|c|}
\hline Variable & $\begin{array}{c}\text { hs-CRP } \\
\text { Low \& High }\end{array}$ & $\begin{array}{c}\text { Ox-LDL } \\
\text { Low \& High }\end{array}$ & $\begin{array}{c}\text { GPx } \\
\text { Low \& High }\end{array}$ \\
\hline $\begin{array}{l}\text { Y-GT (U/L) } \\
\text { Low \& High }\end{array}$ & $\begin{array}{l}r=0.333^{*} \\
O R=5.437\end{array}$ & $\begin{array}{l}r=0.209 \\
O R=2.102\end{array}$ & $\begin{aligned} r & =0.000 \\
O R & =0.000\end{aligned}$ \\
\hline $\begin{array}{l}\text { hs-CRP (mg/L) } \\
\text { Low \& High }\end{array}$ & - & $\begin{array}{l}r=0.042 \\
O R=0.084\end{array}$ & $\begin{array}{l}r=-0.250 \\
O R=3.052\end{array}$ \\
\hline $\begin{array}{l}\text { Ox-LDL (U/L) } \\
\text { Low \& High }\end{array}$ & $\begin{array}{l}r=0.042 \\
O R=0.084\end{array}$ & - & $\begin{aligned} r & =0.375^{\star} \\
O R & =6.932\end{aligned}$ \\
\hline $\begin{array}{l}\text { GPX (U/L) } \\
\text { Low \& High }\end{array}$ & $\begin{array}{l}r=-0.250 \\
O R=3.052\end{array}$ & $\begin{aligned} r & =0.375^{*} \\
O R & =6.932\end{aligned}$ & - \\
\hline
\end{tabular}

* = significant correlation at $\mathrm{p}<0.05 ; \mathrm{OR}=$ Odd Ratio

Analysis report from table 4 showed the significant correlation between $\gamma$-GT with hs-CRP, and there is no significant correlation between $\gamma$-GT with Ox-LDL. Furthermore, $\gamma$-GT levels correlate negatively with GPx, although there is no significant correlation among them. 


\section{CORRELATION ANALYSIS OF $\gamma$-GT/GPX RATIO WITH HS-CRP AND OX-LDL}

Due to the research result sows that there are negative relation between $\gamma$-GT and GPx, it also calculate the ratio of $\gamma$-GT/GPx, and therefore tested for correlation to shows the relation between $\gamma$-GT/GPx ratio with hs-CRP and Ox-LDL. Analysis report showed the significant correlation between $\gamma$-GT/GPx ratio with hs-CRP both of correlation analysis and categorical correlation (table 5).

Table 5. Correlation between y-GT/GPx ratio with hs-CRP and Ox-LDL

\begin{tabular}{c|c|c}
\hline \multirow{2}{*}{ Variable } & Y-GT/GPx ratio & Y-GT/GPx ratio \\
\cline { 2 - 3 } & Correlation $(\mathbf{r})$ & Significant $(\mathbf{p})$ \\
\hline hs-CRP $(\mathrm{mg} / \mathrm{L})$ & $0.596^{\star \star}$ & 0.000 \\
Ox-LDL $(\mathrm{U} / \mathrm{L})$ & 0.133 & 0.368 \\
\hline
\end{tabular}

Table 6. Categorical correlation between y-GT/GPx ratio with hs-CRP and Ox-LDL

\begin{tabular}{l|c|c}
\hline \multicolumn{1}{c|}{ Variable } & $\begin{array}{c}\text { hs-CRP } \\
\text { Low \& High }\end{array}$ & $\begin{array}{c}\text { Ox-LDL } \\
\text { Low \& High }\end{array}$ \\
\hline Y-GT/GPx ratio & $r=0.417^{*}$ & $r=0.042$ \\
Low \& High & OR $=8.593$ & OR $=0.084$ \\
\hline
\end{tabular}

\section{Discussion}

In this large, the major findings of our cross sections study including patients with angiographically defined stable CHD are three-fold. First, the significant correlation was found between $\gamma$-GT and hs-CRP. Second, $\gamma$-GT levels correlated positively with Ox-LDL and inversely with GPx levels. Third, $\gamma$-GT. GPx ratio significant correlated with hsCRP.

This result be in mutual records that written by Emdin, et al said that $\gamma$-GT can mediated trough inflammation process (14).

The study concludes that $\gamma$-GT value, relates a connection with Ox-LDL but this linear relation is not a mean relation. This case appropriate with a research that stated that $\gamma$-GT concentration positively related with F2-isoprostanes (17).

This test result also shows that $\gamma$-GT negatively related with GPx $(r=-0.036)$ even though it not showing any mean linier relation. This case is according to the research done by Lee, et al that stated that $\gamma$-GT inverse relation with the antioxidant concentration (serum carotenoids and tokoferol), but Lee's Research cannot explain whether there are relation that conclude mean or not (17).

Lim, et al had have done a research that study the relation between $\gamma$-GT with few other antioxidant but excluded GPx, this study done to 9083 adult. The result of this study shows that $\gamma$-GT serum has a reverse linear relation and it mean $(\mathrm{P}<0.01)$ with $\alpha$-karoten, $\beta$-karoten, $\beta$-kriptosantin, zeasantin/lutein, likopen, and vitamin $\mathrm{C}$. Vitamin $\mathrm{E}$ has no mean relation with $\beta$-GT serum (16).

GPx is an antioxidant that role for detoxification lipid of hydrogen peroxide (18). GPx enzyme needed by the cellular to maintain itself due to oxidative stress by using GSH to reduce $\mathrm{H} 2 \mathrm{O} 2$ and lipid peroxide become an alcohol form alcohol which is harmless (19).

There are few factors that can reduce the enzyme activity, such as internal and external factors. Beside those two factors, genetic also hold important role in controlling the enzyme activity. So, genetic variation hold important role in the activity and expression of 
GPx, meanwhile in this research not involved a control for genetic variation, until the possibility of test result shows that relation between $\gamma$-GT and GPx that have not shown a mean relation (20).

Correlation Test on every each catagorial variable $\gamma$-GT with hs-CRP, Ox-LDL and GPx shows that there are escalation of $\gamma$-GT value, hs-CRP and Ox-LDL. This result in line with research done by Lim, et al that said there are relation between the escalation of the value of $\gamma$-GT serum with oxidative stress (16). And also study by Lee, et al that said that, there are strong relation between the escalation of value of $\gamma$-GT serum with the inflammation process (CRP) (17).

Explanation above have been proved by Accaouci et al whose explain about $\gamma$-GT is a key enzyme implicated in the homeostasis of intracellular reduced GSH and hence in the regulation of the cellular redox state. $\gamma$-GT-dependent ROS production induces the NF- $x \mathrm{~B}-$ binding and then activation activities. Furthermore, from this study we can show same result that $\gamma$-GT can triggering the inflammation process follow through triggering the reactive oxygen species, which prove by signi $\square$ cant correlation between $\gamma$-GT with hs-CRP and Ox-LDL (12).

Negative Linier correlation between $\gamma$-GT and GPx from this research showed that negative linear relation between $\gamma$-GT and GPx shows that there are inverse relation between those two, it appropriate with a study done by Lee, et al (200 $\square$ )that said that, $\gamma$-GT inversely related with antioxidant concentration (carotenoids serum and tokoferol). According to Lee, et al $\gamma$-GT serum activity can increase the ROS production and trigger the inflammation process, which will suppress the antioxidant activity on cellular level (17). According to other source said that antioxidant activity on cellular level also smitten with genetic factor (20).

Participant $\gamma$-GT $\square$ GPx ratio have a minimum point at 0.26 and maximum point at 6.12 . From the test result there is no difference between $\gamma$-GT $\square$ GPx ratio regarding to gender variation and age cluster, but have a signi $\square$ cant difference to inflammation degree. $\square \mathrm{n}$ this research we observe that $\gamma$-GT $\square$ GPx ratio has a mean linear relation with hs-CRP ( $\mathrm{P} \square 0.0 \square$ ), it strengthen a direct relation between $\gamma$-GT serum and GPx with the escalation of inflammation. $t$ reinforced by Categorical Correlation Test (low and high) between the ratio of $\gamma$-GT $\square$ GPx with hs-CRP. From this correlation test result we get odd ratio point at $\square, \square \square$ this result shows that the patient with stable CHD with a high $\gamma$-GT $\square$ GPx ratio there is chance that $\square, \square \square$ times for increasing the amount of hs-CRP, compared to with the patient with stable CHD which have a low hs-CRP concentration.

This matter be in mutual record with Szmitko et el theory, CRP not only can be used as inflammation indicator only, also can act as disease mediator, this happen because CRP has a direct involvement to formation of pla $\square$ ue pathogenesis, pla $\square$ ue fragility, and also take role in the thrombosis process, and also can be used as endotel dysfunction indicator (20).

\section{Conclusion}

By observe a mean relation the ratio between $\gamma$-GT serum with GPx concerning the escalation hs-CRP, in other word the ratio of $\gamma$-GT $\square$ GPx can be used to predict the existence of inflammation process.

\section{Acknowledgement:}

The authors thanks the Prodia Foundation for Research and Training for the invaluable support in conducting this research. And thank to Catherization from laboratory unit of Haji Adam Malik Hospital, Medan, for technical procedures in collecting samples in this research, especially for Prof. Dr. Sutomo Kasiman, MD., for helping to provide the subjects of this research.

\section{References:}

1. Paolicchi A, Emdin M, Ghliozeni E, Ciancia E, Passino C, Popoff G, Pompella A. Human atherosclerotic plaques contain gamma-glutamyltranspeptidase enzyme activity. Circulation 2004; 109: 1440.

2. Pompella A, Emdin M, Passino C, Paolicchi A. The Significance of Serum Gamma-Glutamyltransferase in cardiovascular Disease. Clin Chem Lab Med 2004; 42: 1085 - 1091.

3. Emdin M, Pompella A, Paolicchi A. Gamma-glutamyltranferase, Aterosklerosis, and Chronic Heart Disease: Triggering Oxidative Stres Within Plaque. Editorial. Circulation 2005; 112: $2078-2080$.

4. Ruttmann E, Brant LJ, Concinm H, Diem G, Rapp K, Ulmer H. Gamma-glutamyltransferase as a Risk Faktor for Chronic Heart Disease Mortality: an Epidemiological Investigation in a Cohort of 163944 Australian Adult. Circulation 2004; 112: $2130-2137$.

5. Witfield JB, Zhu G, Nestler JE, Heath AC, and Martin NG. Clin Chem 2002; 48: 1426 - 1431.

6. Lee DH, Jacobs DR Jr, Gross M, et al. Y-Glutamyltransferase is a Predictor of Incident Diabetes and Hypertention: The Coronary Arthery Risk Development in Young Adults (CARDIA) Study. Clin Chem 2003; 49: 1358 - 1366. 
7. Lee $\mathrm{DH}, \mathrm{Ha} \mathrm{MH}$, Kim JH, et al. Gamma-Glutamyltransferase and Diabetes a 4 Year Follow-Up Study. Diabetologia 2003; 46: $359-364$.

8. Grundy SM. Gamma-Glutamyltransferase Another Biomarker for Metabolic Syndrome and Cardiovascular Risk. Arterioscler Thromb Vasc Biol 2007; $27: 4$ - 7 .

9. Rahman J, MacNee W. Oxidative Stres and Regulation of Glutathione in Lung Inflammation. Eur Respir J 2000; 16: $534-554$.

10. Schulz JB, Lindenau J, Dichgans J. Glutathione, oxidative stres and neurodegradation. Eur. J. Biochem 2000; 267: 4904 4911.

11. Karp DR, Shimooku K, and Lipsky PE. Expression of Y-Glutamyl Transpeptidase Protection Ramos B Cells from OxidationInduced Cells Death. J Biol Chem 2001; 276: 3798 - 3804.

12. Accaoui MJ, Enoui MM, Masson, Dominici, Wellman, Visvikis. Gamma-glutamyltranspeptidase-dependent glutathione Catabolism Result in Activation of NF-kB. Biochem Biophys Res Commun 2000; 276: 1062 - 1067.

13. Dominici S, Visvikis A, Pieri L, et al. Redox Modulation of NF-kappaB Nuclear Translocation and DNA Binding in Metastatic Melanoma : The Role of Endogenous and Gamma-Glutamyltransferase-Dependent Oxidative Stres. Tumori 2005; 89: 426 - 433.

14. Emdin M, Passio C, Michelassi, et al. Prognostic Value of Serum Gamma - Glutamyl Transferase Activity After Miocardial Infarction. Eur Heart J 2001; 22: 1802 - 1807.
15. Lee DH, Gross MD, Jacobs DR Jr. Association of serum caretenoids and tokopherols with $\mathrm{y}$-glutamyltransferase: The Kardiovaskular Risk Development in Young Adults (CARDIA) study. Clin Chem 2006; 50: $582-588$.

16. Lim JS, Yang YH, Chun BY, Kam S, Jacobs DR Jr, Lee DH. Is Serum Gamma-Glutamyltransferase Inversely Associated with Serum Antioxidants as A Marker of Oxidative Stres ?. Free Radic Biol Med 2004; 37: 1018 - 2023.

17. Lee DH, and Jacobs DR Jr. Asociation between Serum Gamma-Glutamyltransferase and C-Reactive Protein. Atherosclerosis 2005; 178: 327 - 330.

18. Haan JB, Witting PK, Stefanovic N, et al. Lack of Antioxidant Glutathione Perixidase-1 Does Not Increase Atheosclerosis in C57BL/J6 Mice Fed a High-Fat-Diet. J Lipid Res 2006; 47: 1157 - 1167.

19. Forgione MA, Cap A, Liao R, et al. Heterozygous Cellular Glutathione Peroxidase Deficiency in the Mouse. Circulation 2002; 106: 1154 - 1158.

20. Me'zes M, Erdelyi M, Shaaban G, Virag G, Balogh K, Weber M. Genetiks of Glutathione Perixidase. Acta Biol Szeged 2003; 47(1-4): 135 - 138.

21. Szimitko PE, Wang $\mathrm{CH}$, Weisel RD, Almeida JR, Anderson TJ, Verma S. New markers of inflammation and endotel cell activation: Part I. Circulation 2003; 108: 1917-1923. 